\title{
EFL Professional Development: Discussion of Effective Models in Literature
}

\author{
Anas Almuhammadi ${ }^{1}$ \\ ${ }^{1}$ English Language Institute, King Abdulaziz University, Jeddah, Saudi Arabia \\ Correspondence: Anas H. Almuhammadi, English Language Institute, King Abdulaziz University, 80200, Jeddah, \\ Saudi Arabia. Tel: 966-565-000-484. E-mail: aalmuhammadi@kau.edu.sa
}

Received: March 1, 2017 Accepted: May 20, 2017 Online Published: May 26, 2017

doi: 10.5539/elt.v10n6p118 URL: http://doi.org/10.5539/elt.v10n6p118

\begin{abstract}
This paper explores the professional development literature in the educational setting. The different literature pieces are aligned to a framework that requires effective professional development to focus on three concepts: content, context, and process. The content focuses on the "what" question in the programs while the context aims to align the content with "where" question. The third component is the focus on the process variables that professional development should follow. This paper tries to add to the English as a Foreign Language (EFL) and English as a Second Language (ESL) fields' literature by presenting categorized overview of relevant works. The different theories include adult learning theory, functional theory, multiple intelligences, twenty-one learning styles, the Australian Government Quality Teaching Program (AGQTP) model and model of teacher change.
\end{abstract}

Keywords: professional development, ESL, EFL, adult learning theory, CCP model

\section{Introduction}

Most studies in professional development in education focus on the process rather than on the content or the context (Almuhammadi, 2015). This means that the focus on the best knowledge, that these programs should provide and the questions related to the environment where training and teaching takes place, are absent. This discussion and presentation of literature will explore some of the scholarly work under the three categories and concepts of context, content, and process or, as I will refer to it as CCP (Almuhammadi, 2015). Context is the environment where professional development takes place while accounting all components of socio-political matrix. The content focus is on the generic knowledge that is provided in professional development programs. Finally, the process, is how these professional development programs are presented. In a previous work that discussed the literature on professional development in the ESL field, Almuhammadi (2015), suggested that effective professional development should focus on the three concepts of content, context, and process rather than focusing mostly on the process. In this paper, there is a presentation of different literary works on ESL adults' professional development categorized under the three components of effective professional development.

\section{Process}

\subsection{Adult Learning Theory}

In the educational setting, professional development helps the delivery of knowledge and promotes competency among instructors (Borko, 2004). To achieve that, planning of effective professional development programs is critical. Effective programs may incorporate a basis of knowledge of the best practices in teaching and learning, effective collaboration (Borko, 2004), and curricula that uses creative and new technologies that encourages interactive learning (Caffarella, 2010). Collaboration encourages the teachers to change their role from transferring knowledge to the role of facilitating the scene where learning takes place which leads to more engagement from learners with the materials that is being taught. Regardless of how trained they are, trainers of professional development programs tend to not apply principles of collaborative learning in teaching adults' learners and their instructional practices (Caffarella, 2010). Professional development trainers do not usually use the best instructional styles in teaching specific audience (Caffarella, 2010).

Other scholarly works suggest that professional development trainers should leave the zones of comfort and become engaged in student-centered instructional practices rather than teacher-centered delivery of knowledge (He, Prater, \& Steed, 2011). One study, that was conducted on professional adult learners, shows that there are 
barriers that stand before learning in adult classrooms (He et al., 2011). The researcher found out that there are five barriers that affect the learning process in professional development programs including "time constraints, financial constraints, workplace culture, application of new knowledge, and competency in accessing electronic literature" (He et al., 2011, p. 120). To categorize these constraints under the three categorizations of this framework, CCP, competency of accessing online literature and application of new knowledge are process variables. Time and financial constraints, and workplace culture are contextual factors.

Professional development programs usually deal with adult learners who value the control over the learning experience and prefer ownership of the process (Knowles, Holton III, \& Swanson, 2014). If adult learners feel that they are not threatened to lose control over learning, the process of acquiring the new knowledge will have a potential of success (Knowles et al., 2014). Shifting professional development training from the trainer's role as the only expert to a more of a facilitator of learners' experiences will increase the positive outcomes of the learning experience and meets the desired transfer of knowledge (Kahl Jr \& Venette, 2010; Knowles et al., 2014). One feature of the adult learning theory is that it supports the use of self-learning that encourages curriculum strategies that are learner-centered which in turn, meets the desire of control over the learning experience that will primarily results in more learning (Kahl Jr \& Venette, 2010; Knowles et al., 2014).

Professional development programs with the only focus on one-size-fits-all application have less success in reaching the targeted outcomes. Using "multimodal approaches to teaching and learning" (Medves et al., 2010, p. 49) may provide better results in knowledge transfer (Medves et al., 2010). It is important to know that "dissemination and implementation alone do not facilitate transfer of learning Transfer of learning needs to be planned to facilitate optimum results" (Caffarella, 2010, p. 134).Professional development goes beyond the learning experience to the level of having an implementation of the new knowledge afterwards.

\subsection{Functional Theory}

The functional Theory suggests that adult learners should be directed to the experience-oriented practices (Trotter, 2006). For adults, the learning experience is much more important and "paramount" (Trotter, 2006). In some adult learning programs, what makes adult learning ineffective is that the learning experience is traditional with assessment that does not support critical thinking, vague goals, weak pedagogy (Boud, Keogh, \& Walker, 1996). Trotter support the idea by saying that:

"small groups of aspiring adults who desire to keep their minds fresh and vigorous; who begin to learn by confronting pertinent situations; who dig down into the reservoirs of their experience before resorting to texts and secondary facts, who are led in the discussion by teacher who are also searchers after wisdom and not oracles, this constitutes the setting for adult education, the modern quest life's meaning" (Trotter, 2006, p.6)

One major component of adult learning is that it should encourage the learner to learn more(Knowles et al., 2014). Adults are more driven by the need to make their own decisions in learning. Content is as valuable as the process of learning to adult learners. This kind of learning should be a meaningful process to the learner and also should be experience-oriented (Boud et al., 1996).

Functional theory relates to professional development by suggesting six major strategies of adult learning: 1) the use of real experience, 2) teaching adults should be more of a mentoring, 3) adults should plan their learning experience, 4) adults' participation in active learning settings, 5) continuous support and available feedback when taking new directions, 6) adult learning aims at developing each adult which requires self-assessment (Boud et al., 1996) (Zepeda, 2014). 


\subsection{Multiple Intelligences}

The multiple intelligences model was developed by H. Gardner (1993) to show how different people learn differently based on their learning preferences or readiness. This model can be categorized under the process factors because it deals with the question of how learning occurs. This model can be applied to the adult learners in the staff development programs. The richness of Gardner's model is in the differences that a staff development should be aware of and how this notion can be delivered to trainees to help them deal with different students learning styles (Gardner, 1993).

While the different intelligences are process factors but some may include contextual factors, such as the naturalistic, linguistic, and the intrapersonal intelligences. Some other intelligence types may deal with content such as linguistic, logical and musical intelligences. The merging between categorization of these intelligences under the themes of content, context, and process may help teachers find ways of improving the teaching based on the different intelligences of learners. There are only two intelligences are taken care of, linguistic, in the forms of writing, speaking, and the logical, which can be found in science (Howard Gardner \& Moran, 2006).

Table 1. Multiple Intelligences (H. Gardner, 1993; Park, 2008)

\begin{tabular}{|c|c|}
\hline Intelligence & Definition \\
\hline Linguistic & $\begin{array}{c}\text { Sensitivity to spoken and written language, } \\
\text { the ability to learn languages, and the } \\
\text { capacity to use language to accomplish } \\
\text { certain goals. }\end{array}$ \\
\hline Logical & $\begin{array}{l}\text { Capacity to analyze problems logically, } \\
\text { carry out mathematical operations, and } \\
\text { investigate issues scientifically. }\end{array}$ \\
\hline Spatial & $\begin{array}{c}\text { Potential to recognize and manipulate } \\
\text { patterns of wide space as well as patterns of } \\
\text { more confined areas }\end{array}$ \\
\hline Kinesthetic & $\begin{array}{c}\text { Potential of using one's while body or parts } \\
\text { of the body to solve problems or fashion } \\
\text { products }\end{array}$ \\
\hline Musical & $\begin{array}{l}\text { Skill in performance, composition and } \\
\text { appreciation of musical patterns }\end{array}$ \\
\hline Interpersonal & $\begin{array}{l}\text { Person's capacity to understand the } \\
\text { intentions, motivations and desires of other } \\
\text { people, and consequentially, to work } \\
\text { effectively with others }\end{array}$ \\
\hline Intrapersonal & $\begin{array}{l}\text { Person's capacity to understand the } \\
\text { intentions, motivations, and desires, fears, } \\
\text { and capacities, and to use such information } \\
\text { effectively in regulating one's own life. }\end{array}$ \\
\hline Naturalistic & $\begin{array}{l}\text { The potential for discriminating among } \\
\text { plants, animals, socks, and the world around } \\
\text { us, as used in understanding nature, making } \\
\text { distinctions, identifying flora and fauna. }\end{array}$ \\
\hline
\end{tabular}


The multiple intelligences theory can be criticized for not being empirically proven, even without strong evidence and researches that may help the spread of using such model, educational institutions are already incorporating some of these intelligences in the classroom settings (Denig, 2004; Howard Gardner \& Moran, 2006; Waterhouse, 2006). The only evidence needed is to empirically prove that teachers' use of these multiple intelligences would benefit their classroom instructional practices. Presenting such theories gives insights of how variations of learning styles exist but need to be taken into consideration in professional development programs.

There were studies that reflect effectiveness of multiple intelligences. One study was conducted on thirty-nine learners to see how they might incorporate and develop a sense of using different multiple intelligences. The researcher observed those learners and concluded that the assessment of learners showed that there are different distinctions in learning styles (Gardner \& Moran, 2006). Learners presented a strength in at least one of the multiple intelligences which reflects that there are different preferences in learning.

Another study was conducted on one district's teachers and was observed for one academic year. Teachers were interviewed and replied to different surveys to see how the professional development on multiple intelligences changed or improved their teaching practices. Findings showed that most teachers viewed the support toward using multiple intelligences in their classroom as valuable. Findings also showed that teachers valued the way they were trained in the professional development sessions which were given in an interactive environment since it gave them a sense of ownership over their learning experience. This study shows that even without strong empirical backgrounds for multiple intelligences model, there are some studies that show how beneficial some studies found this model is in professional development and in teachers' instructional practices (Enstrom \& Danielson, 2006).

This study also supports the notion that professional development is a continuous process that scaffolds theory and practice (Enstrom \& Danielson, 2006). Instructors need to apply what they learn then continue learning which makes practice and instructional changes more of an ongoing action research. The peer collaboration in this study shows how professional training can be developed in different directions and not only by having lectures or experts. Expertise can be built through the negotiation of ideas among peers in staff development sessions (Engstrom \& Danielson, 2006).

\subsection{Learning Styles}

Another learning model that this study will look at is the twenty-one learning styles (Dunn \& Dunn, 1999). The main target of this learning model is on how the learner learns which also means that the focus is mostly on the process without eliminating the content or the context elements. The concept of this model is that it is not prescribed on learners' natural abilities to learn or how intelligent their brains are but rather how they might learn new knowledge by using strategies that they can learn. Critical thinking, solving complex problems, logic, experience-based learning strategies are among these strategies.

As visualized in Figure 1, these twenty-one learning styles are categorized into five main groups.

1. Environmental:

a) Sound: whether a learner prefers to learn while listening or may be a learner needs some silence around.

b) Light: preference of learning in a sunny and shiny light or may be in a soft lightened desk.

c) Temperature: the temperature plays a role in making good learning based on learners' preferences, some might need cool place and some might like warm.

d) Design: whether in circles, or desks facing the lecturer; inside or outside

2. Emotional:

a. Motivation: learning something new might be self-driven or may a learner needs someone or something around to be motivated by.

b. Persistence: the learner may need some follow up but other can focus until they finish the task.

c. Responsibility: some may achieve what is requested from them to do, but others might not take it serious.

d. Structure: some may rely on their abilities but others may request teacher's presence to complete the task by mentoring.

3. Sociological

a. Colleagues: some students may learn better in a group

b. Self: other may like studying alone. 
c. Pair: maybe it is the preference of a learner to learn with a friend.

d. Team: some learners may like to study in an organized team

e. Authority: guidance from an adult may be a condition to learn from some learners

f. Varied: some learners may prefer a mix of all these sociological strategies.

4. Physical

a. Perceptual: how a learner perceives the learning is different; visual; audio, active physical.

b. Intake: eat, drink while learning or may be not are different preferences of learners.

c. Time: if a learner is a morning or evening person; it depends.

d. Mobility: some learners prefer to read while walking, some may like to be setting all the time while learning.

5. Psychological:

a. Analytic - Global: some learners may prefer to look at the whole picture.

b. Cerebral preferences: depends on which side the brain the learnings occurs.

c. Reflective - impulsive: some learners may jump to conclusions very quickly, but others may need time to reach conclusion after an investigative approach

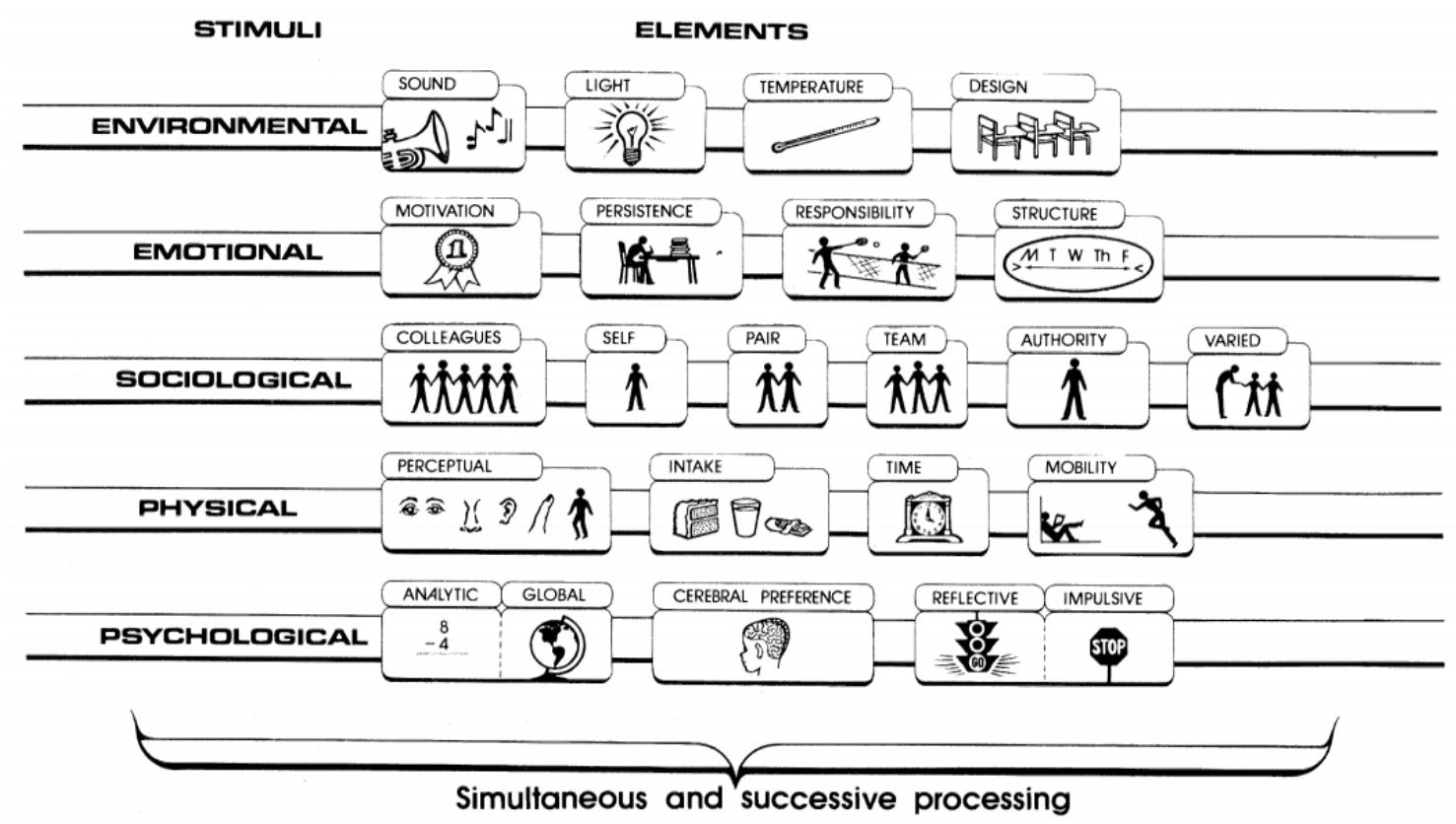

Figure 1.21 Learning Styles (Dunn \& Dunn, 1999)

The concept behind this learning style model is that learners have different preferences in different settings. In addition, it can be said that learners have one main learning preference which can be useful, if known, to enhance the learning experience (Dunn \& Dunn, 1999). All learning models discussed above consider learners' differences but do not provide specific pedagogical suggestions to be implemented. Unlike multiple intelligences theory, (Denig, 2004) believes that Dunn and Dunn's twenty-one learning styles have significant empirical basis to support this model.

As discussed before in this paper, professional development trainers are more concerned about the way they provide the training sessions; the process. H. Gardner (1993) multiple intelligences and Dunn and Dunn (1999) learning styles change that focus from process to a more incorporation of content-focused and context-focused learning. This shift will produce a learning that is consistent with students' preferred learning styles which adds to the strength of teacher instructional practices. 


\section{Context}

\subsection{Model of Teacher Change}

This model for change was presented by (Guskey, 1986). This model shows how the professional development context affect the instructional changes of teachers. There are major goals of this model: 1) to develop the instructional practices of instructors, 2) to change instructors or teachers' beliefs about the learning experience and the necessity of professional development by looking at 3) the change of outcomes in students learning (Guskey \& Sparks, 2004).

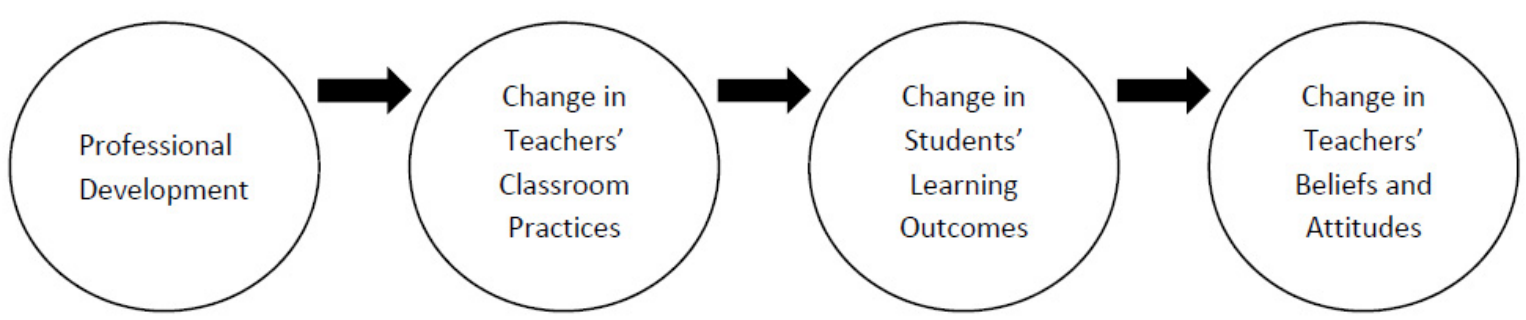

Figure. 2 Model of Teacher Change (Guskey, 1986)

Professional development programs for teachers usually are not effective. There are many reasons for these drawbacks. According to (Guskey, 1986), there are a couple of main reasons for these failures: a) teachers' development plans do not count the encouragement of instructors, b) no theory or model presents how professional development affects teachers' instructional practices. (Guskey, 1986; Guskey \& Sparks, 2004). One way to respond to those suggested failures, the model of teacher change clarifies how focusing of the "process" and "context" is important to the success on professional development programs because it provides the needed motivation to instructors because they will use students' outcomes as guidance to their professional development needs. Instructors' beliefs tend to change when students succeed or fail because they consider it an indicator of the quality of their teaching. One strength about this model is that it shows that instructors' change in attitudes and practices do not happen at the beginning of professional development. That is because instructors consider the good outcomes of their students as a mark of success.

There are some insights that can be taken out of this model. First, professional development of teachers is a lengthy process that needs too much resources to be actively changing(Guskey \& Sparks, 2004). Second, if we consider students' results as the major mark of success, then instructors need to have evaluation that give them the needed feedback which many reflect change or not (Guskey \& Sparks, 2004). Finally, professional development can take time because it is a process that requires continuity.

\section{Content}

\subsection{RISE, Responsive Instruction for Success in English}

There are different models of professional development that language teachers can benefit from. These programs take different styles. The first professional development program can take the teacher through a process of instructional-based decisions that can be made in the classroom. This model was promoted by the National Center for Education Evaluation under the Department of Education. This professional development program is called RISE, short for Responsive Instruction for Success in English (Arens, 2012).

The goal of this professional development program is to provide teachers and instructors with research-based instructional classroom practices that they can be implement in ESL or EFL classes. This program provides content that has empirical basis to teachers without time or effort constraints of looking up on databases or the internet. This program gives teachers an opportunity to scaffold and apply theory into practice as they have guides of changes.

RISE covers content that shows basic theories of English language learning and second language acquisition (Arens, 2012). It also covers instructional and evaluative strategies for different such as formative and summative assessment strategies. This professional development program can be conducted in sixteen hours throughout the school year. It consists of eight units that can be distributed among the eight meetings.

RISE provides teachers with sustained adult training that delivers curriculum-linked and site-based professional 
development (Arens et. al., 2012). It focuses on the three-component categorization of effective programs of professional development; content, context, and process. Teachers tend to dislike professional development programs because they sometime look irrelevant to their practices, knowledge, and interests (Penuel, Fishman, Yamaguchi, \& Gallagher, 2007).

A study was conducted by the Institute of Education Sciences on fifty-two schools in three states on ELL teachers who taught Spanish students for two years. The study employed the RISE professional development program into thirty-four schools as a treatment group. The other eighteen schools were the control group. The results showed that by incorporating instructional strategies and professional development programs, RISE, teachers tend to develop practices ranging from new evaluative strategies, increased students' engagement, diverse use of instructional strategies in the classrooms (Arens et al., 2012).

\subsection{Models I-III of Professional Development}

This model aims at changing the students' outcomes at the first place. The main concern is how teachers change their instructional practices in the classroom through continuous learning. Models I-III are focusing on the level of support to teachers while learning. These models focus on the process of teachers' learning (Professional Development for Language Teachers, 1997)

\subsubsection{Model I}

The first model is a supervised stage where teachers are accompanied by experts in the desired area of change. The program is designed by the contribution of the trainer, the supervisor, the teacher. The sequence of this model's process is spiral, which reflects the on-going process of change. It starts with a training session, followed by a supervised teaching, discussion of observation of instructors' practices. After that, there is another intervention and a training course that can be tailored on the teachers' needs (Professional Development for Language Teachers, 1997). That leads to another similar cycle to start and the spiral effect continue to implement and guide change.

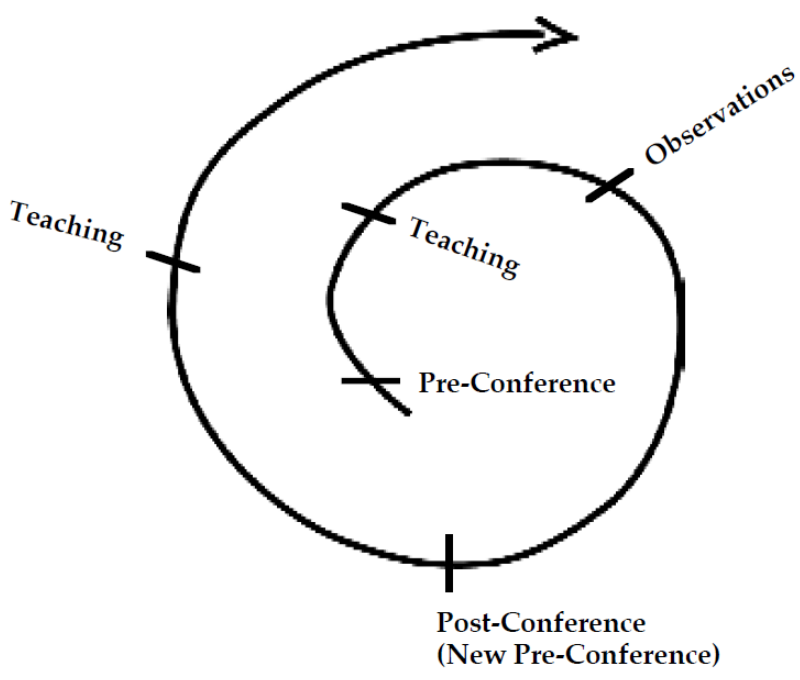

Figure 3. Model I-III (Professional Development for Language Teachers, 1997)

\subsubsection{Model II}

Model II is more advanced because there is no need for an expert, but there is a need for just an accomplished colleague. This model is called the guided model that is based on "peer coaching"(Professional Development for Language Teachers, 1997). In this model, the same spiral process takes place but with one difference. The observation part of this model is not only an expert review, it is now more of a mix between a teacher's own assessment, students' feedback, and the accomplished peer observation. This observation set will decide the second part of the next teaching (Professional Development for Language Teachers, 1997).

\subsubsection{Model III}

The third model suggests that a teacher is now at a level where guidance is not needed but encouraged. This model is called the "self-directed strand" (Professional Development for Language Teachers, 1997) model of teachers' professional development. The spiral mode still existing but the observation component is now 
self-reported. The pre-conference can occur whenever the teacher needs to consult peers or experts about certain issues. The teacher can implement new strategies and practices on their own and test the effectiveness of the new instructional change. This model suggests that teachers can achieve and develop knowledge of the subject-matter gradually (Professional Development for Language Teachers, 1997).

\subsection{The AGQTP Model}

The Australian Government Quality Teacher Program, AGQTP, conducted four studies in the early 2000s to enhance the quality of teachers' practices. Those 4 studies became the research basis for this professional development program (Ingvarson, Meiers, \& Beavis, 2005). More than 3250 teachers participated in those studies and the data analysis was conducted after 80 professional development programs for all teachers. The researchers in the three studies preferred to wait at least three months after last professional development program to make a time for a possible change in teachers' practices.

The researchers developed a professional development model that divided the change factors into categories similar to those of this paper's framework. The model was divided into the following four categories:

a. "1. Contextual factors (e.g. school and administrative support)

b. 2. Structural features of programs (e.g. length)

c. 3. Process features (emphasis on content; active learning; examination of students' work; feedback; follow-up)

b) 4. Mediating variables (level of professional community generated)" (Ingvarson et al., 2005).

These four components were assessed based on the following measures: "1) knowledge, 2) practice, 3) student learning, 4) efficacy" (Ingvarson et al., 2005). The results of the four studies reflected there is a correlation and direct effects of focused content, and assessment on knowledge (Ingvarson et al., 2005). Since feedback was not implemented occasionally in the practices and development programs, there were significant evidence of its effect on other variables including teachers' practice.

As shown in Figure 4, the components that this model includes are broader but more detailed to include background variables. Using this paper's theoretical framework, it can be said that this model is sensitive to context because it contains structural features and the mediating factor of professional development. For the content factors, this model covered knowledge as a major part of the model and it preceded the practice factor. As well as other models, it seems that this model has more favor to the process factors. The active learning, collaborative examination, feedback, collective participation, practice, student learning is among the dominant presence of process factors in this model.

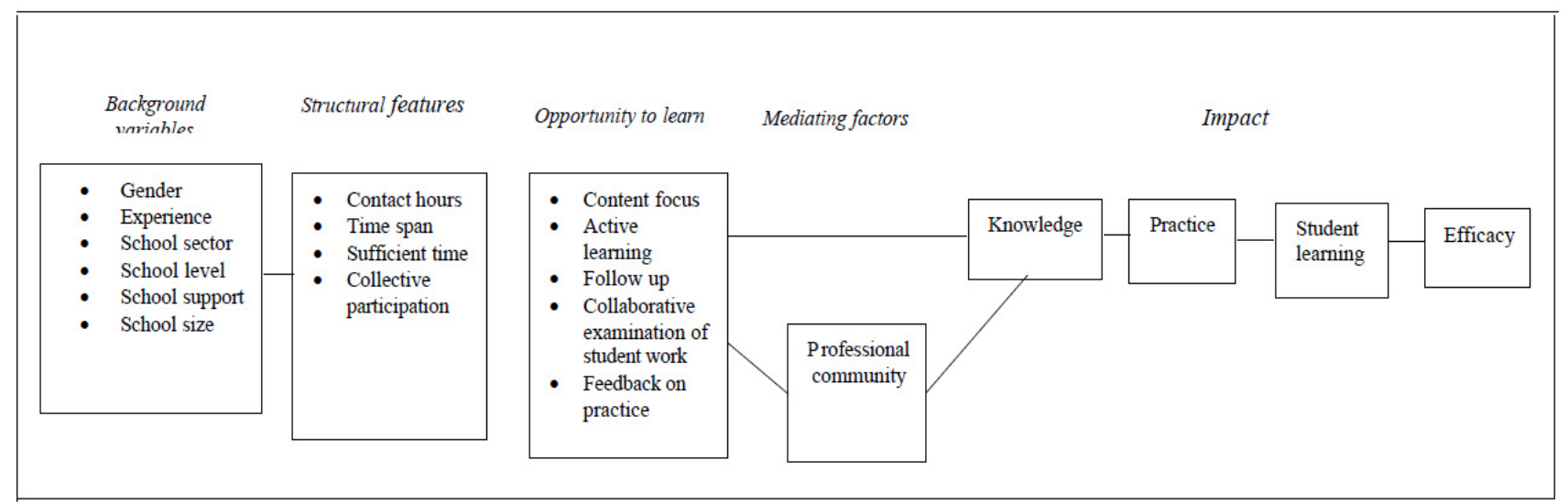

Figure. 4 The AGQTP model (Ingvarson et al., 2005)

It is worth noting that this model shares with the Guskey (1986) model that the learning outcomes of students us is a major sign of success. The results of the four studies, that this Australian model was built on, show that the content focus of professional development program is a step that encourages teachers to participate in these programs. In other words, when teachers feel that the content of professional development program is related directly to what they teach, and what their students should learn, then they feel engaged. 
The other major finding of the studies that can be drawn is that the active learning aspect of the professional development program showed a direct effect on the knowledge of teachers that will result in better instructional practices. Another study shows the same relationship between active learning of professional development programs and the knowledge of teachers (Garrett et al, 2001). Garret studied a group of teachers by implementing strong content-focus sessions that resulted directly into teachers' engagement (Garrett et al, 2001). The similar results in Garret's study and the AGQTP model is that of efficacy, when teachers' beliefs about professional development changed after they acknowledged the difference in their students' outcomes (Garrett et al, 2001; (Ingvarson et al., 2005).

At the end of this presentation of literature, it is worth noting that professional development models are available to ESL/EFL administrations and instructors in different fields like human resources and administrative specializations. Having different models that are interdisciplinary and interconnected with other fields will bring more value to the ESL/EFL field. This paper is just one way to bring value to this area of research.

\section{References}

Almuhammadi, A. H. (2015). English language instructors' perceptions of their professional development and instructional practices at King Abdulaziz University. The Florida State University.

Borko, H. (2004). Professional development and teacher learning: Mapping the terrain. Educational researcher, 33(8), 3-15. https://doi.org/10.3102/0013189X033008003

Boud, D., Keogh, R., \& Walker, D. (1996). Promoting reflection in learning: A model. Boundaries of adult learning, 1, 32-56.

Caffarella, R. (2010). Devising transfer of learning plans. Designing and assessing learning experiences, 215-236.

Denig, S. J. (2004). Multiple intelligences and learning styles: Two complementary dimensions. Teachers College Record, 106(1), 96-111. https://doi.org/10.1111/j.1467-9620.2004.00322.x

Dunn, R. S., \& Dunn, K. J. (1999). The Complete Guide to the Learning Styles Inservice System: Allyn and Bacon.

Engstrom, M. E., \& Danielson, L. M. (2006). Teachers' perceptions of an on-site staff development model. The Clearing House: A Journal of Educational Strategies, Issues and Ideas, 79(4), 170-173. https://doi.org/10.3200/TCHS.79.4.170-173

Gardner, H. (1993). Multiple Intelligences: The Theory in Practice: Basic Books.

Gardner, H., \& Moran, S. (2006). The science of multiple intelligences theory: A response to Lynn Waterhouse. Educational psychologist, 41(4), 227-232. https://doi.org/10.1207/s15326985ep4104_2

Guskey, T. R. (1986). Staff development and the process of teacher change. Educational researcher, 15(5), 5-12. https://doi.org/10.3102/0013189X015005005

Guskey, T. R., \& Sparks, D. (2004). Linking professional development to improvements in student learning. Research linking teacher preparation and student performance, 11-21.

He, Y., Prater, K., \& Steed, T. (2011). Moving beyond 'just good teaching': ESL professional development for $\begin{array}{llll}\text { all teachers. Professional development in education, } 37(1), & \text { 7-18. }\end{array}$ https://doi.org/10.1080/19415250903467199

Ingvarson, L., Meiers, M., \& Beavis, A. (2005). Factors affecting the impact of professional development programs on teachers' knowledge, practice, student outcomes \& efficacy. Professional development for teachers and school leaders, 1. https://doi.org/10.14507/epaa.v13n10.2005

Kahl Jr, D. H., \& Venette, S. (2010). To lecture or let go: A comparative analysis of student speech outlines from teacher-centered and learner-centered classrooms. Communication Teacher, 24(3), 178-186. https://doi.org/10.1080/17404622.2010.490232

Knowles, M. S., Holton III, E. F., \& Swanson, R. A. (2014). The adult learner: The definitive classic in adult education and human resource development: Routledge.

Medves, J., Godfrey, C., Turner, C., Paterson, M., Harrison, M., MacKenzie, L., \& Durando, P. (2010). Systematic review of practice guideline dissemination and implementation strategies for healthcare teams and team - based practice. International Journal of Evidence - Based Healthcare, 8(2), 79-89. https://doi.org/10.1111/j.1744-1609.2010.00166.x 
Park, M. A. (2008). Factors affecting the transfer of differentiated curriculum from professional development into classroom practice: University of Southern California.

Penuel, W. R., Fishman, B. J., Yamaguchi, R., \& Gallagher, L. P. (2007). What makes professional development effective? Strategies that foster curriculum implementation. American educational research journal, 44(4), 921-958. https://doi.org/10.3102/0002831207308221

Professional Development for Language Teachers. (1997). Retrieved from Austin, TX:

Waterhouse, L. (2006). Inadequate evidence for multiple intelligences, Mozart effect, and emotional intelligence theories. Educational psychologist, 41(4), 247-255. https://doi.org/10.1207/s15326985ep4104_1

\section{Copyrights}

Copyright for this article is retained by the author(s), with first publication rights granted to the journal.

This is an open-access article distributed under the terms and conditions of the Creative Commons Attribution license (http://creativecommons.org/licenses/by/4.0/). 